\section{DR. C. W. GÜMBEL ON DEEP-SEA MUD}

DR. C. W. GUMBEL has recently published an important paper, containing an account of some highly interesting investigations on Deep-sea Mud. Sir R. Murchison and Professor Huxley provided him with a large quantity of mud, taken up from the Atlantic at lat. $29^{\circ} 36^{\prime} 54^{\prime \prime} \mathrm{N}$., and long. $18^{\circ} 19^{\prime} 48^{\prime \prime}$ W., at a depth of about 2,350 fathoms. This he first cleared, by long. continued washing, from all sea-salts soluble in water; then he divided it, by filtering, into three parts. In the first Foramini. fera and larger organisms predominated; the second consisted of a sediment easily distinguished from the first, fine but heavy; the third was fine and flaky, remaining lightly suspended in water, and consisting almost exclusively of Bathybus, Coccoliths, Coccospheres, together with other organisms of the smallest kind (Diatoms, Kadiolaria, Sponge-spicules, and a very few of the smallest Foraminifera). "Dried to about $100^{\circ} \mathrm{C}$." says Dr. Gümbel, " Io per cent, of the mud consisted of large Foraminifera; I'3 per cent. of fine, heavy mud; and 88.7 per cent. of finest Bathybius mud. The ro per cent. part consisted mostly of Globigerinza, which occurred in an astonishing variety of forms, from the smallest shapes to figures of a considerable size, and could easily be distinguished as Gl. bulloides and Gl. inflata. Next to these in number were Orbulina unizersa, Cristellaria crepidula, Truncatulina lobatula, Discorbina rosacea, Rotalia soldanii, $R$. orbicularis, Pulvinulina eleganss; P. micheliana, Nonionina umbilicata, Polystomella crispa, Litnola globigeriniiformis, with many other (but more dismem. bered) species. Along with these there were individual specimens of large Radiolaria, Siliceous Sponge-spicules, Diatoms, shells of Ostracoda, torn pieces of sponge and (very rarely) of Echinodermata, and fragments of wood, which were very de. cidedly distinguishable. It is a question whether the latter was a part of the apparatus used in raising the mud. It is in the highest degree remarkable that all traces of Bryozoa, corals, and firm pieces of more highly-organised animals, were wanting, or at least were very rare.

"The fine heavier mud which composes the sediment contains, for the most part, inorganic elements, with fragments which consist essentially of carbonate of lime, and which, on being dissolved in acids, leave behind cuticular membranes and flakes, which partly gave the reaction of conchiolin. It appears to follow from this, that these pieces of calcareous matter, althungh I could discover by the microscope no structure in them, are essentially de. rived from pounded molluscous shells. The remaining portion, which was insoluble in diluted acids, was composed of irregular, for the most part lump-shaped, granules of quartz, of clearly recugnisable scales of nica, of dust, and of magnetic iron, which could be drawn out by the magnetic needle; of single red. blue, and dark green transparent pieces of mineral; and of grains of crystal, of a peculiarly dark irxidescent brilliance which I can refer only to Labradorite. The polarisation and stauroscope apparatus was used for the purpose of determining these inorganic ingredients.

"These inorganic elements of the Deep-sea Mud, found at such a distance from land, appeared to me worthy of the greatest consideration. Their origin can scarcely be ascribed to the loosening of the perhaps rocky bottom of the sea, at the point where it was sounded. They rather prove that inorganic sub. stances, which are derived from the rocky masses of the land by inechanical destruction, are conveyed by ocean currents to parts of the sea the farthest removed from land. This would render casily explicable the admixture of inorganic elements in many vcean sediments of ancient times. The explanation of clayey or marly interpositions would be made much less difficult. If heavy masses of mineral are transported so far, how much more casy would be the transportation of clayey mud which remains so lightly suspended in the water! It is almost self-evident low quantities of clay or marl may be brought to a stand at certain parts of the high sea, marked out beforehand by the direction of the ocean currents and the configuration of the bottom of the sea, and when the direction of the currents changes, may come to form even alternate strata of chalk and marl. We thus obtain a mode of explaining the formation of many marl deposits, which is at once natural and simple.

"The third portion of the Deep-sea Mud is worthy in a high 1egree of the interest both of the zoologist and the geologist, whilst it gives scope for many far-reaching theories. If w'e first analyse it microscopically, the substance, which resembles a white clay mud, resolves itself, apart from the intermingled minutest cilobigerince and some few other Foraminifera, into a heap of little granules, the so-called Coccoliths (Discoliths and Cyatroliths), and of gramulous fiaky little lumps, the so.called Bathybius, compared with which all other ingredients, - the siliceous-shelled Diatoms, and Radiolarica, and also perhaps the so-called Cocco* spheres and other small organic bodies excepted,-are of very secondary importance.

"The part of the Deep-sea Mud which is made up of Diatoms and Radiolaria, together with Sponge spicules, is of especial importance, becatise it consists to no inconsiderable extent of silica, and appears to be the source from which the siliceous concretions in many chalk formations have drawn their materials. That these form no inconsiderable part of the composition ot Deep-sea Mud may be clearly seen by removing the chalk by means of acids, and the organic matter by heat or by sulphuric acid. There then become visible the most beautiful forms of Diatoms, with especial frequency, Gallionella, Coscinodisci, and Navicula, more rarely Actinocyoli, Pleturosioma, Rhabdonema, Grammatophora, and others, of which many, concealed in the network of granulous Bathybizs masses, were formerly scarcely visible. Many forms of extremely beautiful Radioluria were also seen, together with simple Sponge-spicules. Lastly, we remark some slight fragments of plants, which may belong to the species of Saprolegnia and Protoccus."

Speaking of the Coccoliths and the Bathybizss, Dr. Gümbel says he is in a position to confirm the conclusions of Profs. Huxley, Carpenter, and Haeckel with respect to their organic nature. Iil a note he adds, "I have aiready stated my opinion on this subject (NATURE, April 1870) but must here rectify a mistake in that communication, namely, that the organic matter of the Coccoliths yields with iodine, blue, therefore cellulose, reaction. This colouring, I am now convinced, is not the consequence of chernical action, but a phenomenon of refracted light, such as occurs with small thin leaves or membranes when greatly magnified."

After detailing some ohservations, nicroscopic and chemical, on Bathybius and Coccoliths, Dr. Giimbel proceeds ro speak of the fur. ther distribution of the latter. "First," he says, "on looking through the Algæx, Hydrozoa, Polyps, Corals, \&c., which occur on shallow sea-coasts, such as may easily be met with in every botanical and zoolovical collection, I succeeded in numerous instances in finding Coccoliths in the places where they had grown, and not seldom, Buthybizs at the same time. These investigations were extended to points on the coasts of almost all seas, and now', instead of the statement lately made that the organisms in question thrive only at a depth of 5,000 feet, I am in a position to assert on a proved fact, that Coccoliths (Buthybius\} occul in all seas and at all depths. This deprives these minute bodies of a certain air of wonder with which they were surrounded, as the offspring of the profoundest and most secret depths of the ocean; but by their astonishingly wide distribution and their vast numbers, which stamp them as one of the must essential members of rock-forming substances, they gain infinitely in scientific interest."

Dr. Gümbel maintains that the distribution of Coccoliths in time is not less remarkable than the present distribution in space. There is proof, he says, that they are to be found in "almost all sedimentary formations." Referring to their distribution in various formations, be says :- "But besides the Coccoliths another ingredient demands attention. In the case of the chalk of Mendon, rich in Coccoliths, if the carbonate of lime be removed by means of diluted acids, there remains a fiaky and cuticular residie, in which are found thin, transparent flakes, full of the smallest granules, and resembling Bathybius in a higl degree. This places their organic nature beyond question, and firmly establishes their relationship with the Bathybius. The imperishableness of this substance is indeed very remarkable." After slating that the Cccouliths occur in all the soft marls and limestones of the Jurassic and Liassic furmations--"The Muschelkalk," continues Dr. Cuimbel, "appeared for a long time to be proof against every experiment. Every specimen of marl which I examined was apparently free from Coccoliths. At last I had the good fortune to discnver traces of them in a somewhat impure piece of rock-salt from Wilhelmsglück. Even here they show themselves extremely sparingly, but in the company of flakes, which are not unlike Bathybius. To the present time I have in vain examined the similar rock-salts of Berchtesyaden and Stessfurt ; and as yet indications of Cocculiths in the Permian formation and the Coal-measures are wanting. On the other hand, the soft marls of the mountain limestone of Regnit\%losinl, the soft marls of the Conodont strata of the Baltic provinces, the Trenton marl of New York, and even the silicenus limestone of the Potsdam sandstone, contain some traces, although to an extremely small extent. 
"These facts all point to the conclusion that in the majority of calcareous marine deposits, the Coccoliths originally formed a more or less essential part of the calcareous masses, and that in thick or granulous, and particularly ancient limestone rocks, they can no longer be perceived, either on account of the opaque character of the rocks, or because they have been made by some change wholly or in part unrecognisable, or have been altogether destroyed. I have been able by some experiments to throw further light upon this subject. That these smallest organic bodies can be recognised in hard limestones only in the rarest cases, even when it contains them in great numbers, I convinced myself by means of thin slices, which I made from Deep-sea Mud, thoroughly dried and rendered hard by repeated soaking in diluted Canada balsam and by heating, and also from writing chalk, made hard in the same way, and rich in Coccoliths The infinite numbers of finest granules and rings are so massed together, one over the other, that it must be regarded as an extremely rare case when a Coccolith is clearly seen here and there at the very thinnest edges."

\section{THE BRITISH ASSOCIATION}

\section{SECTIONAL PROCEEDINGS}

\section{Section A.-Mathematical and Physical Science}

On a new Electro-Magnetic Anemometer and the Modeof Using it in Registering theVelocity and Pressure of the Wind.-Mr. J. J. Hall.

The anemometer consists of two parts, viz, - velocity apparatus and registering apparatus. The first consists of a set of Robinson's hemispherical cups, which communicate their motion downwards into a brass box, where it is reduced in angular velocity, and causes a contact disc or commutator (in which two platinum contact pins are fixed equidistant from one another) to revolve in $\frac{1}{1}$ th mile. An insulated metallic lever, having a platinum working face, stands on either side of the disc, so that upon the completion of every $\frac{1}{50}$ th mile one or other of the rontact pins comes in contact with the two levers, thus uniting them and completing the circuit. The levers are raised a few degrees and then fall back to their normal position ready to be taken up by the next pin, and so on. The recording apparatus consists of a train of wheels and pinions working in a frame or between two brass plates, the arbors of which project through a dial-plate whereon the circles and figures are engraved and carry the hands. These wheels are driven by a weight attached to a line wound round a barrel, and a locking-pin disc (the pinion of which works in the frist wheel) is released at every contact of the cupapparatus by an electro-magnet which unlocks the pin-disc and allows the first hand to advance $\frac{1}{50}$ th mile on the graduated dial by a jump similar to the minute hands in remontoire clocks. By turning on a "strike-silent" stop a hammer lever is brought into connection with the escapement and strikes a bell at every contact. By this arrangement the observer has nothing to do but to notice the seconds-hand of his watch or chromometer while he counts the number of times that the bell is struck, each of which corresponds to the five-hundredth part of a mile, and by a formula arranged (and exhibited) by Mr. Hall (who has also arranged a comprehensive series of tables for use with this instrument) the hourly velocity may be readily deduced. In noting velocities extending over long periods of time, the instrument is read in the same manner as the ordinary cup and dial anemometer, or as a gas meter. By means of the formula before mentioned (although the unit of measurement in this instrument is five-hundredths) the observer may arrive at results as near the truth as if the instrument were capable of registering the one-thousandth part of a mile, while the great advantage lies in the fact that the battery power is less called into action, from which we may infer its elemental duration will be considerably longer.

A Magnetic Paradox. - Mr. S. Alfred Varley, Assoc. Inst. C. E. The author stated he had termed the instrument a Magnetic Paradox because the phenomenon exhibited by it was the apparent repulsion of soft iron by a magnet. The apparatus consisted of a compound magnet in a box, and when pieces of soft iron were placed on the box over the poles they became magnetic by induction and were attracted by the magnet; but if a soft iron bar not by itself magnetic was approached near to the pieces of iron, they leapt away from the magnet in the box and became strongly attached to the soft iron bar, the pieces of iron appearing to be repelled by the magnet and attracted by the fron bar. The author stated the explanation demonstrated the duality of the magnetic force, and it would also prove, did we not already know it, that magnetic force was transmitted only by induction. He stated that if a piece of soft iron were placed over the poles of a magnet, the magnet developes the magnetic forces resident in the iron by separating them, and the iron is altracted only by virtue of the forces existing in the iron itself, and to the extent to which the forces are separated. If the magnet be bent, bringing the lower pole round and over the piece of soft iron, the magnetic forces resident in the soft iron will be more developed : but if the piece of soft iron be midway, it will not be attracted, as the forces on either side are equal and balance; another attraction will, however, be manifested if one pole be nearer to the piece of iron than the other. If, instead of bending the magnet as just described, the piece of soft iron placed over the magnet be approached by a soft iron bar, the magnetic forces separated and rendered active in the piece of iron will develop the magnetic forces resident in the iron bar, and if the bar opposed no resistance to the assumption of the magnetic condition, it would exert an attractive force for the piece of soft iron equal to that exerted by the magnet, provided always that the bar was at the same distance. It was stated that as the mass of iron in the iron bar was much greater than that of the piece of soft iron, the resistance opposed by the bar to polarisation was comparatively small, and might be disregarded, and consequently it followed thit as the dual forces resident in iron are equal, and the one force cannot be developed without equally developing the other; when the iron bar was approached nearer to the piece of soft iron it became attracted, leaping away from the magnet and attaching itself to the iron bar, and this notwithstanding that the attractive force exhibited by the iron bar has been called into being by the magnet in the box, which is nearer to the piece of soft iron than it is to the iren bar. The iron bar also collected the magnetic rays of force issuing from the magnets, and consequently it exerted a greater attraction for the piece of soft iron than any individual magnet forming part of the compound magnet. This was shown by placing a piece of soft iron on the pole of one of the magnets and removing it from the pole by the superior attractive force of the iron bar. It was also shown that if only the thickness of a picce of writing-paper were placed between the magnets and the piece of soft iron, the appearance of repulsion could be prevented.

\section{Section B.-Chemical Science}

On the Separation from Iron Furnace Cinder of Phosphoric Acid for Minurial Purposes. - Mr. James Hargreaves. While the author was engaged in an attempt to produce a good serviceable steel direct from phosphoric pig-iron, by the use of nitrate of soda, the fact forced itseif upon his attention that phosphorus had previously been too much looked upon as something to be got rid of, and not sufficiently as sometling to be got hold of; and that to effect the latter would be the best means of effecting the former. When phosphoric pig-iron is converted into malleable iron, the phosphorus is, in great part, transferred to the refinery and puddling furnace cinder in the form of phosphate of iron, the amount varying with the composition of the pig-iron which yields it. The refining and puddling furnace cinder from Cleveland pig-iron generally contains from 3 to 7 per cent. of phosphoric acid, which is from one-fourth to one-half the amount contained in good commercial soluble phosphate of lime. This cinder is sometimes again used for the manufacture of pig-iron, but the product is of small commercial value on account of the accumulation of phosphorus in it. The concentration of the phosphorus from the pig-iron into the cinder in the form of phosphate of iron renders it more easy and practicable to separate, when the preparation of compounds of phosploric acid is the object in view, as there is a smaller bulk of material to be treated to obtain a given amount of this product. The phosphoric acid may be separated either in the form of soluble superphosphates of lime and magnesia, or of the alkaline tribasic phosphates.

On the Retention of Organic Nitrogen by Charcoal. - Mr. Edward C. C. Stanford, F.C.S. In this paper the author submitted some incomplete researches, as a first instalment of what promises to be a wide field of inquiry, viz., the action of char. coal on organic nitrogenous matter. He was desirous of knowing whether or not a loss of nitrogen occurs when that form of matter remains in contact with charcoal, and if so, what becomes of it. If any loss occurs, it would invalidate the process recommended by the author at the Exeter meeting of the Association, viz., that of using charcoal as a means of securing the 